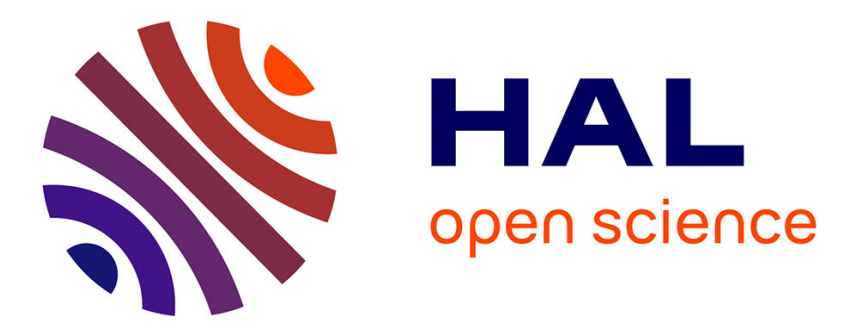

\title{
Paleointensity of the Geomagnetic Field During the Last 80,000 Years
}

\author{
Emmanuel Tric, Jean-Pierre Valet, Piotr Tucholka, Martine Paterne, Laurent \\ Labeyrie, Francois Guichard, Lisa Tauxe, Michel Fontugne, ean-PierreValet
}

\section{- To cite this version:}

Emmanuel Tric, Jean-Pierre Valet, Piotr Tucholka, Martine Paterne, Laurent Labeyrie, et al.. Paleointensity of the Geomagnetic Field During the Last 80,000 Years. Journal of Geophysical Research, 1992, 97 (B6), pp.9337. 10.1029/91JB01620 . hal-03543415

\section{HAL Id: hal-03543415 \\ https://hal.science/hal-03543415}

Submitted on 26 Jan 2022

HAL is a multi-disciplinary open access archive for the deposit and dissemination of scientific research documents, whether they are published or not. The documents may come from teaching and research institutions in France or abroad, or from public or private research centers.
L'archive ouverte pluridisciplinaire HAL, est destinée au dépôt et à la diffusion de documents scientifiques de niveau recherche, publiés ou non, émanant des établissements d'enseignement et de recherche français ou étrangers, des laboratoires publics ou privés. 


\title{
Paleointensity of the Geomagnetic Field During the Last 80,000 Years
}

\author{
Emmanuel Tric, ${ }^{1}$ Jean-Pierre Valet, ${ }^{1,2}$ Piotr Tucholka, ${ }^{3}$ \\ Martine Paterne, ' LAURent Labeyrie, ${ }^{1}$ Francois Guichard, \\ LISA TAUXE, AND MIChEL FONTUGNE
}

\begin{abstract}
High-resolution records of the relative paleointensity of the geomagnetic field have been oblaned from five marine cores. Three duplicate records were used to estimate the regional coherency of the data within a single area (Tyrrhrenian Sea) while the two others document the field variations in the eastern Mediterranean and the southern Indian Ocean. Careful investigations of distinct rock magnetic parameters have established the downcore uniformity of the sediments in terms of magnetic mineralogy and grain sizes. The time-depth control was provided by oxygen isotopes, and small-scale variations in the deposition rates were constrained by means of tephrachronology. The synthetic curve calculated from the Mediterranean records provides a continuous record of the intensity variations during the last 80,000 years $(80 \mathrm{kyr})$, which correlates well with the sparse volcanic data available for the period $0-40$ kyr. The fact that identical behavior is seen in both data sets and that they also compare quite well with results from a core collected in the Pacific Ocean establishes the truly dipolar character of these variations. The dipole field moment is characterized by large-scale changes as shown by the existence of pronounced drops (at 39 and $60 \mathrm{kyr}$ ) alternating with periods of higher intensity. The record suggests a periodic nature for these intensity variations; however, the period studied is not sufficiently long to state this conclusively. These results demonstrate the potential of sediments for such studies and constitute a first step towards obtaining a global paleointensity record over a long period of time.
\end{abstract}

\section{INTRODUCTION}

The intensity changes of the geomagnetic field are reasonably well documented for the period covering the last 10,000 years $(10 \mathrm{kyr})$ from a wide number of archeomagnetic studies [Barton et al., 1979; Kovacheva. 1980, 1982; McElhinny and Senanayake, 1982]. Before this epoch, archeological materials are not available, but a few absolute paleointensities have been obtained from volcanic materials. Lava flows provide instantaneous readings of the field at the time of the volcanic eruptions; however, because of the episodic nature of volcanic events, the record obtained from lava flows is extremely spotty. The construction of a composite continuous record is thus severely hindered by the difficulties of obtaining long volcanic sequences and by the large uncertainties in establishing the precise chronology of the successive flows.

Long and continuous sequences with precise chronological control are required to document the time constants involved in the long-term variations of the dipole field. Marine sediments are associated, in principle, with the continuous process of deposition and have the advantage of being able to be precisely dated by oxygen isotopes. However, the use of sediments for paleointensity studies is delicate. The processes accompanying the magnetization of sediments are neither clearly understood

\footnotetext{
1 Centre des Faibles Radioactivités, laboratoire mixte CNRSCEA, Gif-sur-Yvette, France.

2 Now at Institut de Physique du Globe Paris, France.

3 Laboratoire de Géophysique, Université Paris XI, Orsay,

4 Geological Research Division, Scripps Institution of Oceanography, La Jolla, California.
} France.

Copyright 1991 by the American Geophysical Union.

Paper number 91JB01620.

0148-0227/91/91JB-01620\$05.00 nor very well constrained, since they depend on environmental conditions, lithology (grain size, mineralogy, etc.) and, ultimately, on postdepositional factors. However, the magnetization has been shown to be linearly related to the field intensity, and relative paleofield determinations can be obtained after normalizing properly the contribution of these other factors. The sequences used for paleointensity determinations should have homogeneous and invariable magnetic properties over their full length. Several reliable paleointensity determinations have been derived from sedimentary sequences, including during field reversals [Opdyke et al., 1973; Valet et al., 1988; Laj et al., 1988], and recently, conclusive results have been published which are in good agreement with the archeological data set covering the last 15 kyr [Constable, 1985; Constable and Tauxe, 1987; Tauxe and Valet, 1989].

The aim of the present study is to extend the global record of the geomagnetic field intensity over the last $80 \mathrm{kyr}$. The approach consists, first, of obtaining duplicate records from the same area in order to determine the reproducibility of the results. Records from different regions can then be compared and evaluated as a group. As a first step this paper summarizes the results obtained from four cores in the Mediterranean Sea.

\section{MEASUREMENTS AND ROCK MAGNETIC PROPERTIES}

\section{Natural Remanent Magnetization}

Ten cores distributed in the Mediterranean and three cores from the Indian Ocean were initially selected from areas characterized by deposition rates of at least $10 \mathrm{~cm}$ per 1000 years in order to provide records with a good temporal resolution. A first sampling was performed using the technique of "U" channels [Tauxe et al., 1983]. The top part of the cores (i.e., the first meter below the seafloor) could not, however, be sampled due to a large water content and/or the presence of coring disturbances.

The measurements (taken at intervals of $1 \mathrm{~cm}$ ) and stepwise demagnetization of the $U$ channels (at 4,8 and $16 \mathrm{mT}$ ) by alternating fields (AF) were conducted on the pass-through 
system of the Scripps Paleomagnetic Laboratory. Continuous measurements of the low-field susceptibility $(\chi)$ were performed also with the long-core "Bartington" system mounted in line with the magnetometer. At the end of this preliminary investigation, five cores were selected for further detailed studies based on the stability of the directions upon demagnetization and the regularity of the downcore changes in directions, magnetization intensity and low-field susceptibility. The locations, lengths and water depths of these five cores are summarized in Table 1 and Figure 1.

In order to assess the reliability of these sediments for paleointensities, we undertook a detailed investigation of the magnetic properties of the sediment. An average of 60 discrete samples were taken in the five or six first sections (each section being $1.5 \mathrm{~m}$ long) of every core by pushing plastic cubes $\left(8 \mathrm{~cm}^{3}\right)$ into the sediment. A total of 1600 specimens were subjected to measurements, including stepwise demagnetization of the natural remanent magnetization (NRM), stepwise acquisition and demagnetization of the anhysteretic remanent magnetization (ARM) and saturation isothermal remanent magnetization (SIRM), measurements of the lowfield susceptibility, Curie temperature analyses, $X$ ray analyses, and microscopic studies from magnetic separates.

The measurements of the NRM were done in the shielded room of the Centre des Faibles Radioactivités using a threeaxis LETI magnetometer. About $\mathbf{3 0}$ pilot specimens per section were selected and completely demagnetized by alternating fields with a minimum of nine steps. The remaining samples were demagnetized in four or six successive steps (usually at $10,15,20,25,30$, and $40 \mathrm{mT}$ ). The demagnetization diagrams (Figure 2) are in general of very good quality. Most of them are characterized by a characteristic remanent magnetization decreasing linearly towards the origin with a medium destructive field (MDF) between 15 and $30 \mathrm{mT}$. Complete removal of the magnetization occurs between 40 and $65 \mathrm{mT}$. In $20 \%$ of the samples a soft secondary component is present and was easily removed after 5 and $10 \mathrm{mT}$.

\section{Magnetic Mineralogy and Grain Sizes}

Stepwise acquisition of isothermal remanent magnetization was performed on 30 pilot samples per section. Complete saturation was observed in fields of $0.25 \mathrm{~T}$, while the MDF was lower than $30 \mathrm{mT}$. Such characteristics are compatible with the presence of magnetite but do not identify this mineral unambiguously since similar features can be exhibited by iron sulfides. Thermomagnetic analyses were performed on magnetic separates obtained by circulating a slurry within the polar pieces of a Frantz electromagnet. The heating curves in Figure $3 a$ reveal the presence of a single magnetic phase with a

TABLE 1. Locations and Lengths of Five Cores Selected After the Preliminary Analyses

\begin{tabular}{cccc}
\hline Core & Latitude & Longitude & Length, m \\
\hline KET 82 51 & $39.48^{\circ} \mathrm{N}$ & $14.17^{\circ} \mathrm{E}$ & 9.0 \\
MD 84 528 & $42.11^{\circ} \mathrm{S}$ & $53.04^{\circ} \mathrm{E}$ & 16.3 \\
MD 84629 & $36.04^{\circ} \mathrm{N}$ & $33.08^{\circ} \mathrm{E}$ & 9.0 \\
DED 87 07 & $39.41^{\circ} \mathrm{N}$ & $13.35^{\circ} \mathrm{E}$ & 16.4 \\
DED 87 08 & $39.42^{\circ} \mathrm{N}$ & $13.34^{\circ} \mathrm{E}$ & 19.7 \\
\hline
\end{tabular}

MD: Marion Dufresne cruise; DED: Dedale cruise ; and KET: Etna cruise.
Curie temperature between $550^{\circ} \mathrm{C}$ and $580^{\circ} \mathrm{C}$. The cooling curves are characterized by lower Js values, probably resulting from the conversion of magnetite into hematite after heating in air. $X$ ray diffraction analyses confirmed the presence of magnetite, which was clearly identified by several peaks at $2.52,1.49,2.09,1.62$ and $1.71 \AA$. No other magnetic mineral was detected (Figure $3 b$ ).

Several methods have been suggested for the determination of particle size variations of magnetite. King et al. [1982] have constructed a phenomenological model based on a plot of anhysteretic magnetization versus $\chi$. These parameters may be used to determine variations in magnetic grain size and concentration. Changes in the $A R M / \chi$ ratio imply changes in grain size, with higher ratios indicating smaller grain sizes, while changes in ARM and $\chi$ with constant ratio correspond to changes in concentration of magnetic material only. It can be seen in Figure 4 that no significant variation of $A R M / \chi$ is observed in any core except for a few peaks characterized by variations exceeding a factor of 3 which yield large and incoherent results in the final NRM/ARM or NRM/ $\chi$ ratios. The corresponding samples were therefore ruled out. It must be noticed that this limit is much more stringent than the requirements given so far in the selection procedures for paleointensities [King et al., 1983], where a factor of 10 cutoff limit was proposed.

An alternative method proposed by Petersen et al. [1986] is based on a comparison of the MDF values associated with the ARM and the SIRM. The ARM has coercivities higher than SIRM in all records, indicating the dominant role of the monodomain or pseudo-monodomain grains. Microscopic examinations performed on magnetic separates revealed the presence of $0.5-3 \mathrm{~mm}$ magnetite grains with similar size distribution in all samples.

These experiments have shown that magnetite in monodomain or pseudo-monodomain grains is present as the only carrier of remanent magnetization in every core. The downcore variations in the concentration of this mineral have been detected by scrutinizing the variations in the ARM, SIRM and low-field susceptibility (Figure 5). Except for a very limited number of levels close to sandy, ash or sapropel layers the downcore profiles of the three parameters are identical and do not show variations larger than a factor of 2 . The similarity between these three distinct parameters involving different families of magnetic grains indicates that the relative distribution of the grain sizes remained constant.

\section{DETERMINATION OF THE RELATIVE PALEOINTENSITY}

The ARM, the low-field susceptibility and the SIRM have been used in paleointensity studies in order to normalize the amount of magnetic material [Johnson et al., 1975; Nesbitt, 1966; Kawai and Nakajima, 1973]. The latter two are not strictly related to the monodomain or pseudo-monodomain grains but respond more to the fraction of multidomain grains. Levi and Banerjee [1976] proposed that the ARM is a more adequate parameter because it is mainly sensitive to the grain fraction involved in the NRM, and King et al. [1983] have developed an approach based on ARM measurements for selecting sediments adapted to such paleointensity studies. The basic requirements for this type of study are demonstrating the presence of magnetite which is carrying the remanence and the homogeneity of the sediment with respect to grain concentration and grain sizes. The results of the measurements described above have shown that the cores satisfy these conditions and are suitable for relative paleointensity studies. In addition, we have compared the NRM and ARM demagnetization curves. Following a suggestion by Levi and 

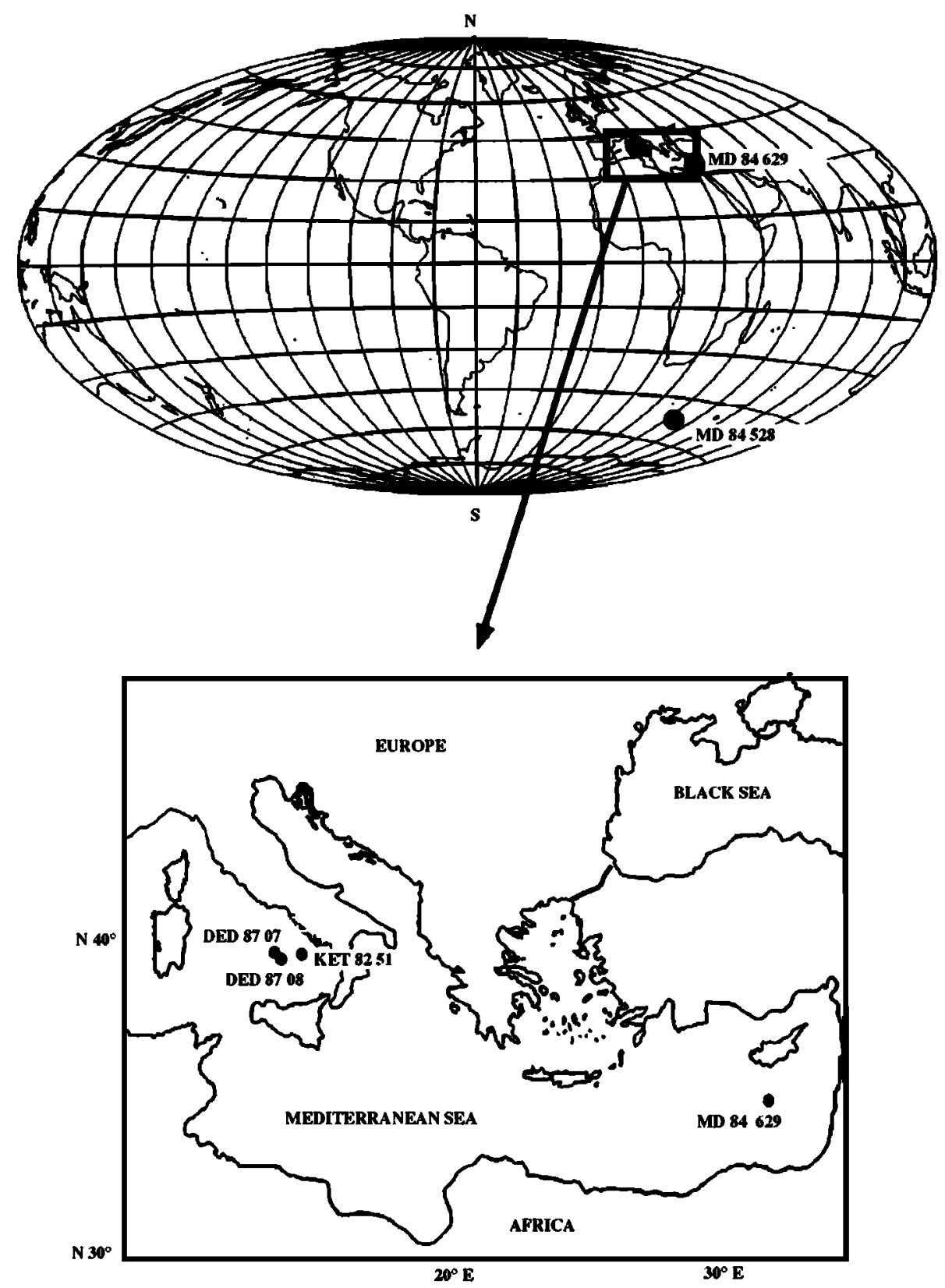

Fig. 1. Map showing the locations of the cores.

Banerjee [1976], we assume that the identical demagnetization behaviors of these two parameters provide a good indication that both magnetizations are carried by similar families of grains. In $95 \%$ of the cases the slopes of the two curves are similar as well as the MDF values (Figure 6). This test was conclusive.

Based on the constant ratios between the distinct rock magnetic parameters, the ARM, SIRM or $\chi$ could equally well be used to normalize the magnetization intensity. The NRM/ARM, NRM/SIRM, and NRM/ $\chi$ ratios for the discrete samples have been plotted in Figure 7 together with the NRM $/ \chi$ ratio from the continuous measurements. Any level of demagnetization between 10 and $40 \mathrm{mT}$ would have been appropriate. We used the ARM and the NRM intensities after
$20 \mathrm{mT}$ for the single samples (and after $16 \mathrm{mT}$ for the U channels) because these values are close to the MDF and at these steps any secondary component of magnetization has been removed. A consequence implicit in the method used here is that the absolute values of the vertical scale are meaningless The distinct records of the same core have been arbitrarily matched to the same scale as the continous measurements through the use of a multiplicative factor. As could be expected, the same features are reproduced by every set of measurements. leaving us confident about the reliability of the measurements as well as about the success of the normalization. Differences between the results of normalization with distinct parameters may reflect inhomogeneities within the sediment and suggest an estimate of the limit of confidence in the results on the order of about 0.2 on the artificial scale in Figure 7. 1.e. about 20\% of maximum field value. 

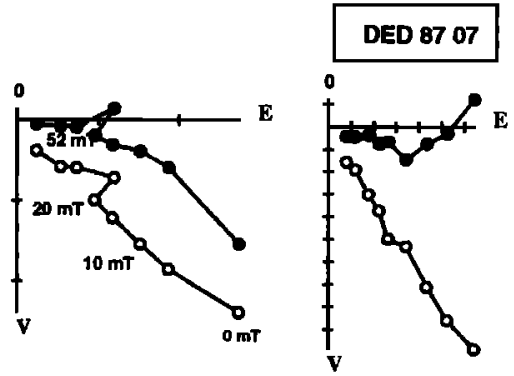

$154 \mathrm{~cm}$

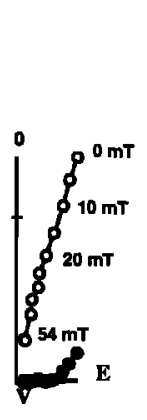

$96 \mathrm{~cm}$

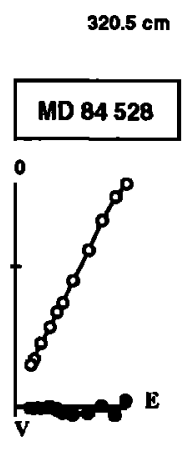

$164.3 \mathrm{~cm}$

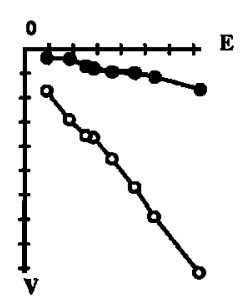

$449.5 \mathrm{~cm}$
MD 84629

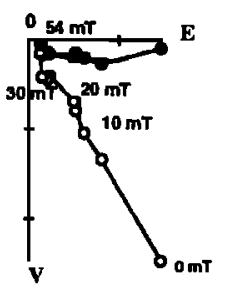

$204.4 \mathrm{~cm}$

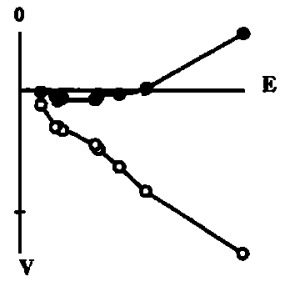

$315.5 \mathrm{~cm}$

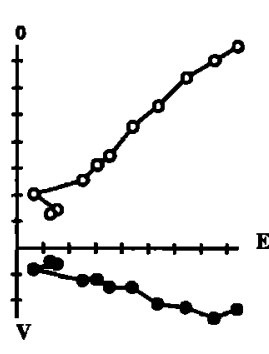

$222.2 \mathrm{~cm}$

Fig. 2. Orthogonal vector projection of alternating field demagnetization for samples from core. The declinations have not been corrected from core orientation. The solid (open) symbols represent the projection of the magnetic vector onto the horizontal (vertical) plane.

\section{RESULTS}

\section{Dating and Time Resolution}

Oxygen isotope measurements performed on cores $\mathrm{MD}$ 84629 (eastern Mediterranean) and MD 84528 (south Indian Ocean) provided the time scale [Imbrie et al., 1982]. No isotope studies have been performed on the three cores from the Tyrrhenian Sea. However, the cores KET 8251, DED 8707 and DED 8708 were collected in the same area. The two last cores, taken at the same site, duplicate core KET 8004, which has a complete oxygen record and many tephra layers that have been analyzed, dated and correlated with similar layers exposed on land [Paterne, 1985; Paterne et al., 1986]. The sequence of tephras found in KET 8004 was easily indentified in the three cores studied; in addition, several marine ash layers occurring over the past $80 \mathrm{kyr}$ were readily correlated with well known (and K-Ar dated) terrestrial deposits [Paterne, 1985; Paterne et al., 1986; Paterne et al., 1988; Tucholka et al., 1987]. Tephrochronology was therefore used to correlate the four records from the Tyrrhenian Sea with very high accuracy (Figure $8 a$ ). A total of 6 to 22 stratigraphic levels could be dated with precision for every core, providing a generally satisfactory time-depth control (Figure $8 b$ ). In addition, these

correlations are also assessed by the presence of organic-rich levels which are related to the well-known sapropel layers identified in the whole eastern Mediterranean Sea [Ryan, 1972; Cita et al., 1973].

The mean deposition rates calculated from these correlations are generally around $10 \mathrm{~cm}$ per thousand years; however, the values obtained within individual intervals between dated horizons sometimes differ significantly. As the number of such levels is relatively large, the time scale of these changes is well constrained. Based on these estimates the final
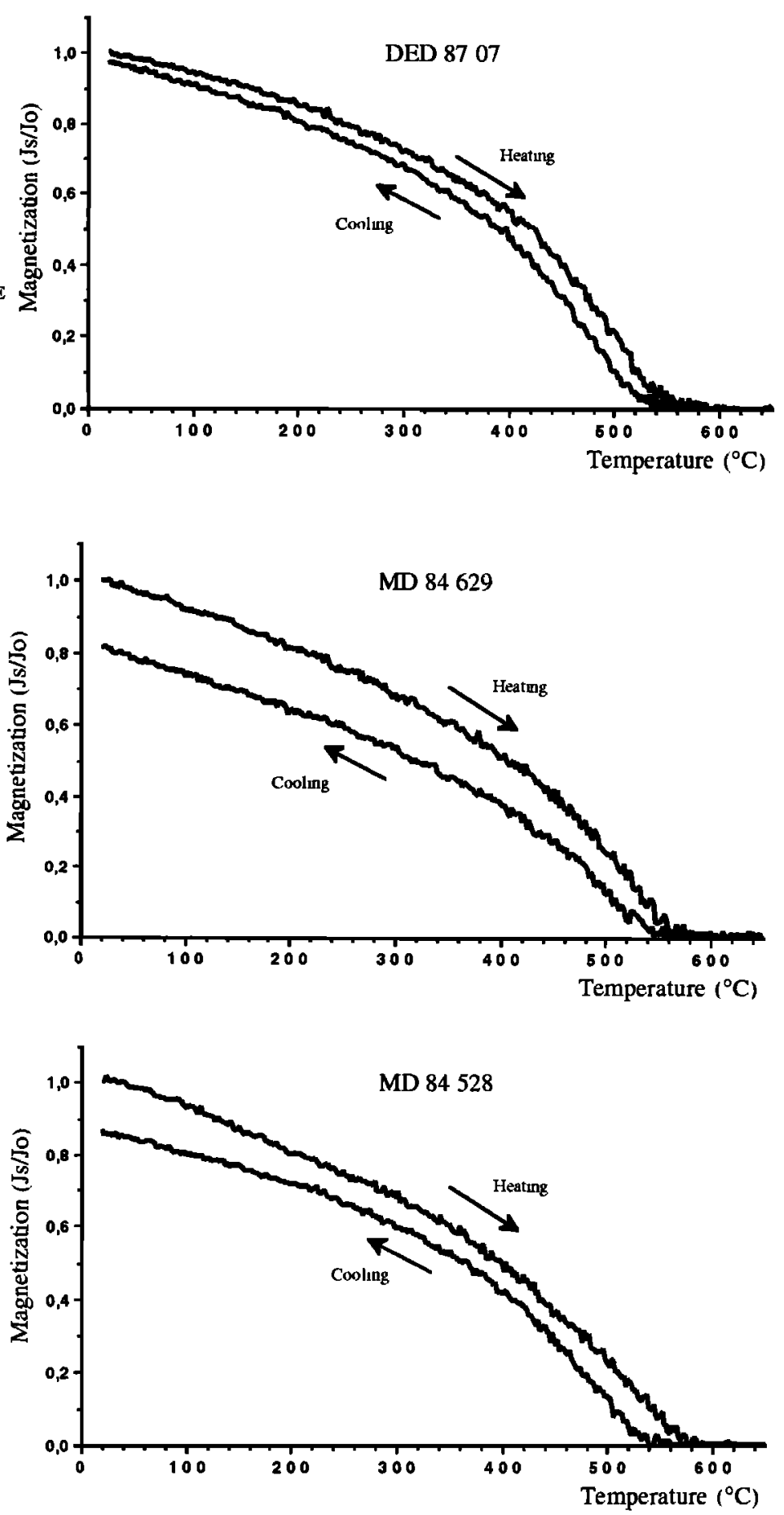

Fig. 3a. Results of thermomagnetic analysis performed under nitrogen atmosphere on samples from cores DED 8707, MD 84629 and MD 84528. The heating and cooling curves are reversible and characterized by the Curie point of magnetite at $580^{\circ} \mathrm{C}$. 


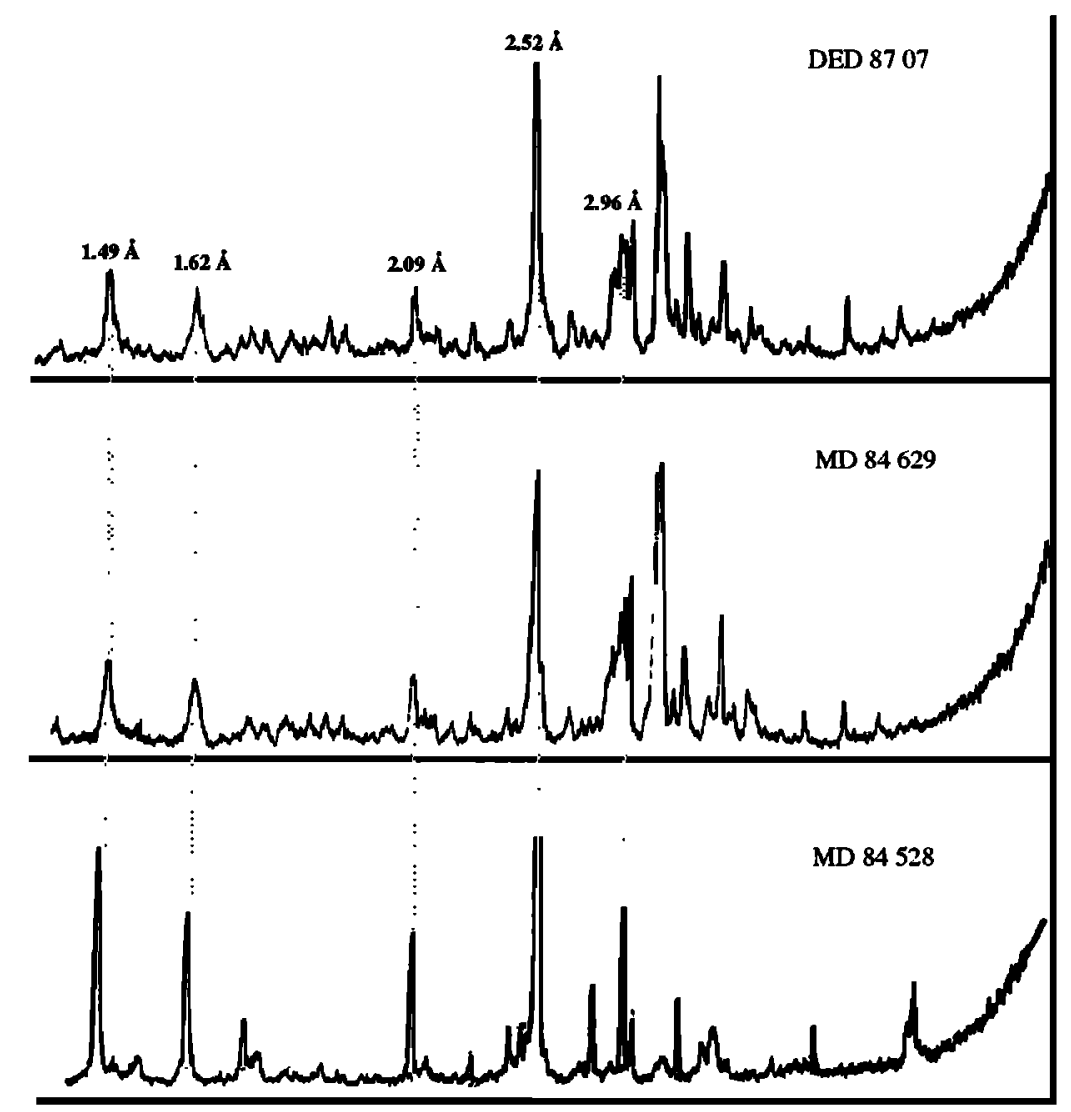

Fig. 3b. Typical $\mathrm{X}$ ray diffraction spectra obtained from magnetic extracts of distinct cores. The magnetite is unambiguously identified by five intensity peaks.

time versus depth correspondence was established at time increments of 200 years by linear interpolation.

The long-core measurements of the "U" channels, excluding data within $5 \mathrm{~cm}$ of the ends of each section, have a temporal resolution of less than 400 years (for a deposition rate of $10 \mathrm{~cm}$ per thousand years) [Tauxe and Wu, 1990], which is not significantly different from the 200 years averaged over the size of a single sample.

\section{Reliability of the Records of Geomagnetic Intensity Variations}

Before going further into the interpretation of the records of normalized NRM intensity in terms of geomagnetic field behavior we must examine the possible influence of factors other than field intensity.

It must first be shown that the record of intensity is not influenced by changes in the magnetic properties of the sediment. The four measured rock magnetic parameters (NRM, ARM, $\chi$ and SIRM) have characteristic relationships as shown in Table 2. The correlation coefficients between parameters characterizing the quantity of the magnetic fraction in the sediments (ARM, $\chi$, SIRM) are high and positive (Student's ttest shows $p \ll 0.001$ ). The NRM intensity shows only a weak correlation with these parameters. The NRM varies by a factor of 10 , while the other parameters only change by a factor of 2 or 3. It is thus clear that the first-order variations of the NRM intensity do not depend on changes of the magnetic properties and are therefore mainly related to the variation of the geomagnetic field.

Several authors have reported strong correlations between the evolution of the magnetic properties in ocean sediments and indices of climatic changes. Some of these paleomagnetic studies [Robinson, 1986; Bloemendal et al., 1988] reveal that glacial periods are characterized by a high magnetic concentration due to low carbonate productivity, while interglacial horizons show low magnetic concentration and high carbonate content following the retreat of the polar front and the re-establishment of coccolith floras. If such effects prevailed for the sediments investigated in this study, the rock magnetic parameters should be correlated with the $\delta^{18} \mathrm{O}$ record. We therefore compared the $\delta^{18} \mathrm{O}$ record with the susceptibility record of core MD 84629. The plots shown in Figure 9 do not demonstrate any convincing evidence for a correlation between $\chi$ and the $\delta^{18} \mathrm{O}$ record. However, within the investigated period the amplitude of these fluctuations is low, and as shown above, the paleointensity pattern is not influenced by the rock magnetic parameters used for the normalization.

\section{Relative Paleointensity}

As a first step we compared the individual records obtained within the same area (Tyrrhenian Sea). The three paleointensity curves obtained from cores DED 8707, DED 8708 and KET 8251 shown in Figure 10 are virtually identical on all but the shortest time scales. As noted above, the vertical scale is arbitrary and the values of the NRM/ $\chi$ ratios differ slighty between cores. This is likely to be a consequence of various local environmental conditions. Indeed, distinct families of magnetic grains yield different ratios between the magnetization intensities and the external field. The coherency of these records from the same area establishes their reliability in terms of geomagnetic behavior. Since the average time 

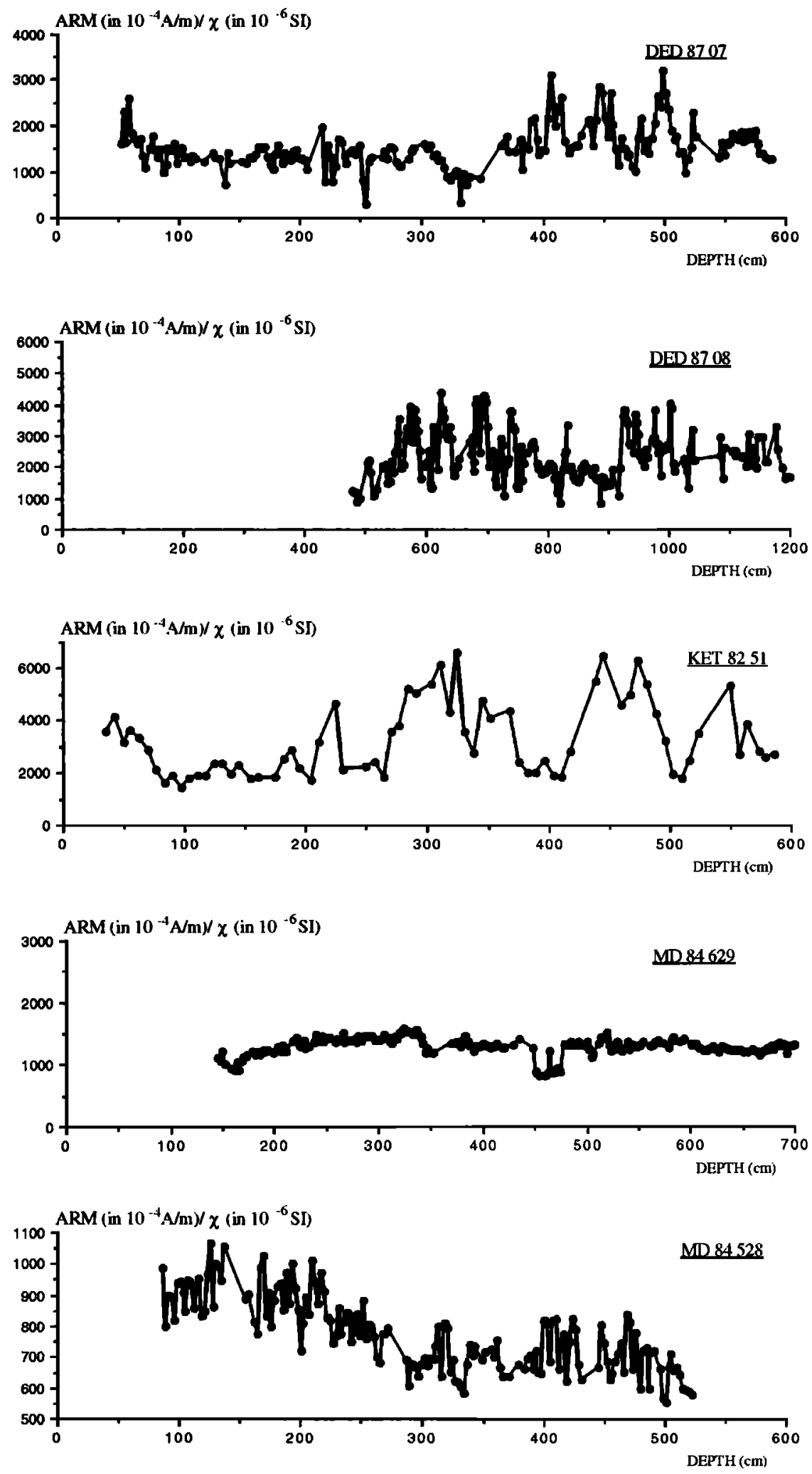

Fig. 4. Downcore evolution of the $\mathrm{ARM} / \chi$ ratios showing the absence of significant changes in the grain sizes.

resolution is close to 400 years, the shorter-period nondipole changes are generally filtered from the data.

However, this time span is not long enough to average out completely the effects of the secular variation at a single site. We therefore compared these results with those from the eastern
Mediterranean and the south Indian Ocean (MD 84629 and MD 84528) (Figure 10).

Every core from the Mediterranean Sea depicts similar profiles of the NRM/ $\chi$ ratio with two maxima at about $39 \mathrm{kyr}$ and $60 \mathrm{kyr}$ and a broad maximum centered at $52 \mathrm{kyr}$. Although 

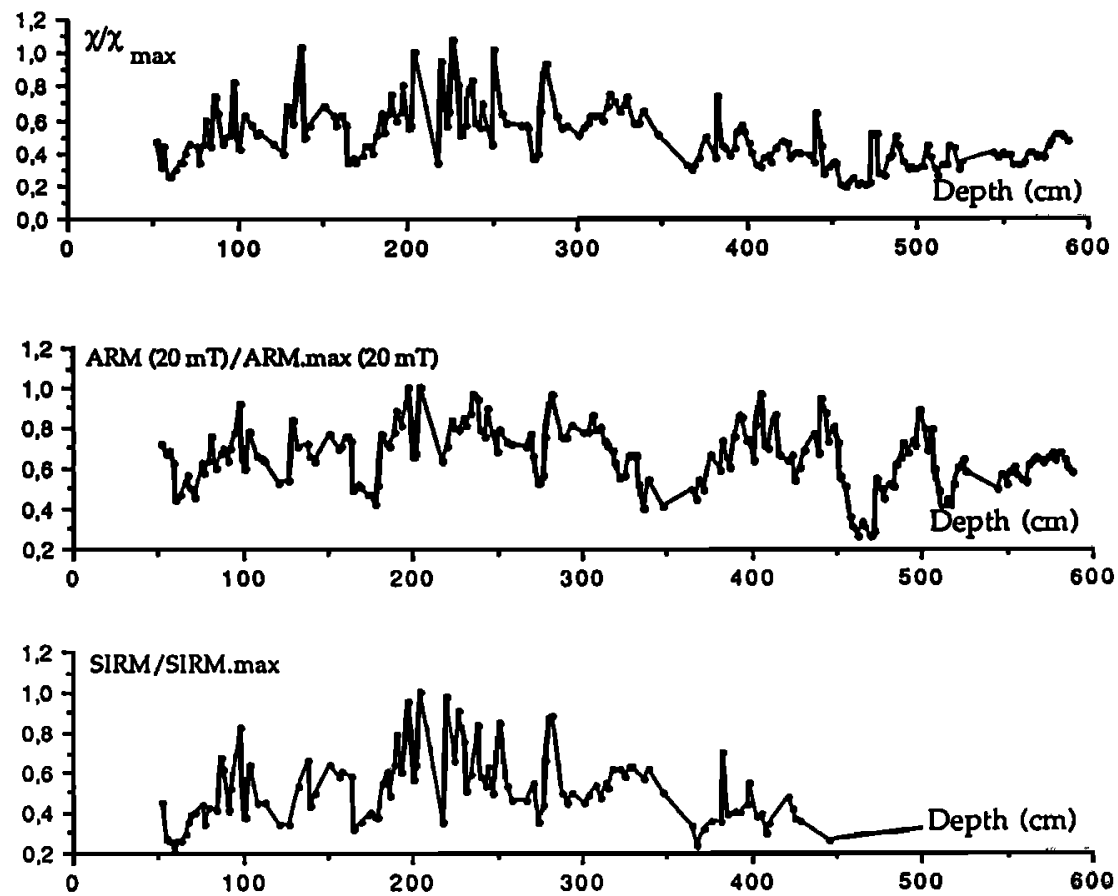

MD 84629
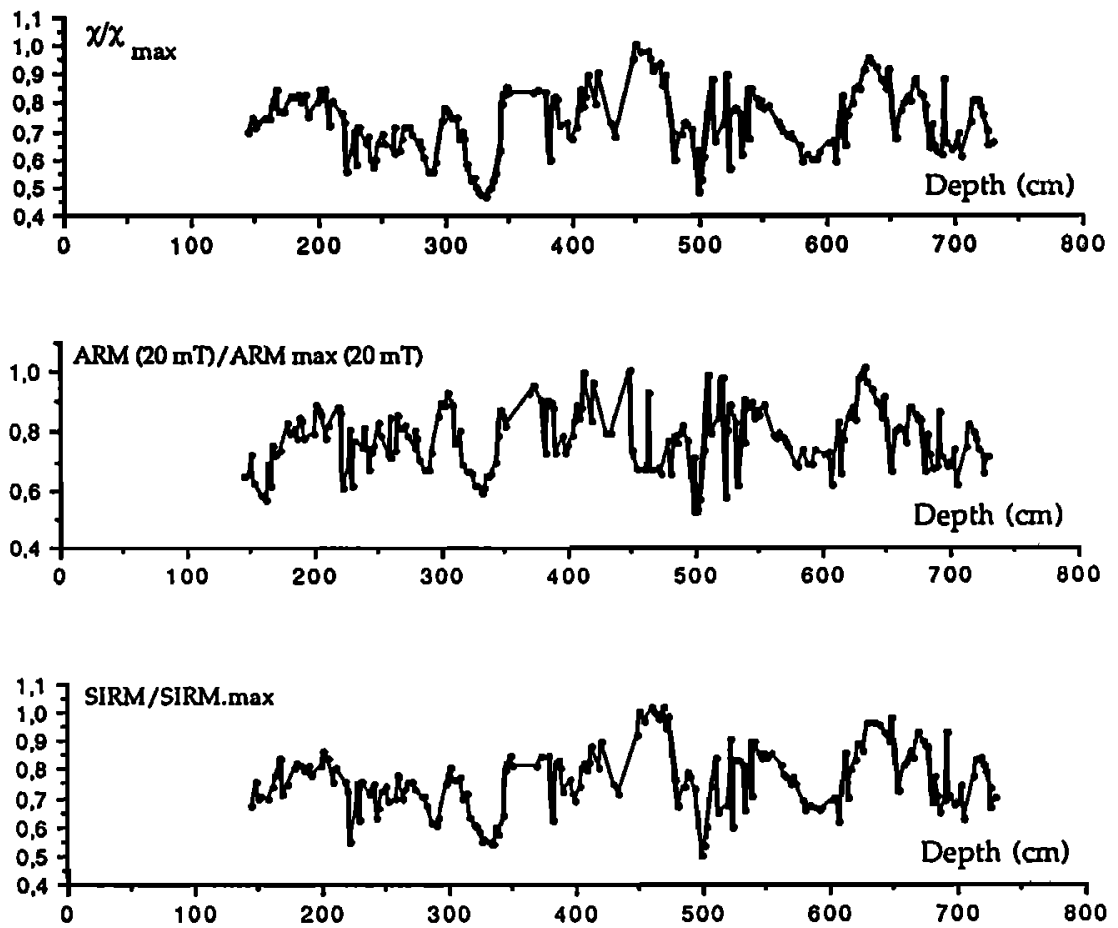

Fig. 5. Downcore variations of three distinct rock magnelic parameters in cores DED 8707 and MD 84629 .

the two minima at $39 \mathrm{kyr}$ and $60 \mathrm{kyr}$ are present also in the record from the south Indian Ocean, the rest of the record bears less resemblance to the Mediterranean cores. Such differences may be due to nondipole local effects and/or to rapid variation in the deposition rate. Additional records from this area are thus required to distinguish between these possibilities.
It was thus reasonable to combine the four data sets from the Mediterranean Sea into a global average. To achieve this calculation, the amplitudes of the signals were constrained within the same minimal and maximal values depicted in every core at 39 and $52 \mathrm{kyr}$. The overall record obtained within successive intervals of 200 years by performing a linear 


\section{KET 8251}
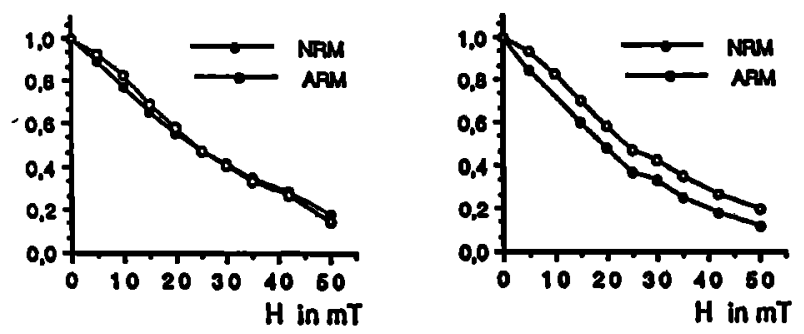

DED 8707
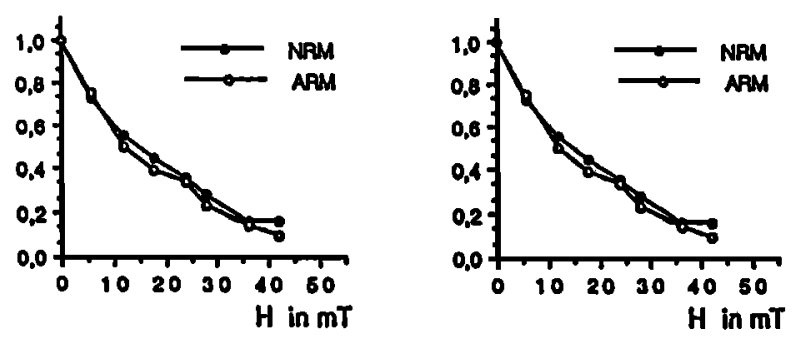

MD 84528
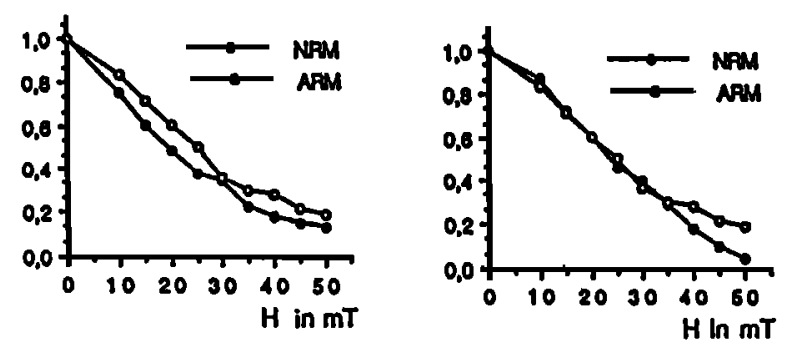

MD 84629

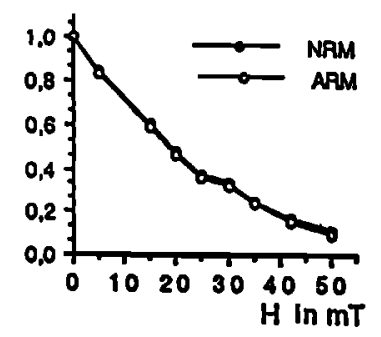

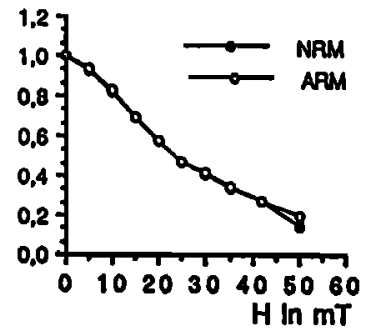
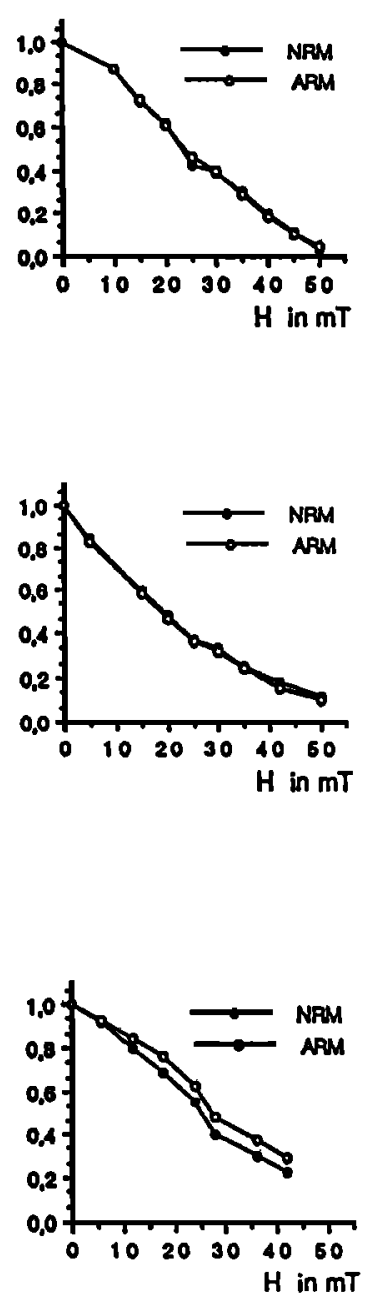

Fig. 6. Comparison between alterning field demagnetization curves of the NRM and the ARM from the same samples. The fact that similar variations are revealed by every parameter rules out the presence of large variations in the distribution of grain sizes. Both magnetizations are characterized by identical coercivities, which suggests that the same families of magnetic grains are involved.

interpolation of the data is shown in Figure 11 together with the envelope representing the mean standard deviation within every interval (characterized by at least three measurements). This curve represents our approximation of the relative paleointensities within the period $0-80 \mathrm{kyr}$. The envelope corresponds quite well to the main curve and is significantly lower in amplitude than the amplitude of the intensity fluctuations. Some detailed features observed over shorter periods may, however, be less obvious, and these uncertainties must be kept in mind in the interpretation of the results.

If the paleointensity record obtained from these marine sediments is correct, it should compare with the archeomagnetic and volcanic data sets obtained within the interval 0-50 kyr B.P. [Coe et al., 1978; Barbetti and Flude, 1979; McElhinny and Senanayake, 1982; Salis, 1987; Roperch et al., 1988; Chauvin et al., 1991]. All the drilling 

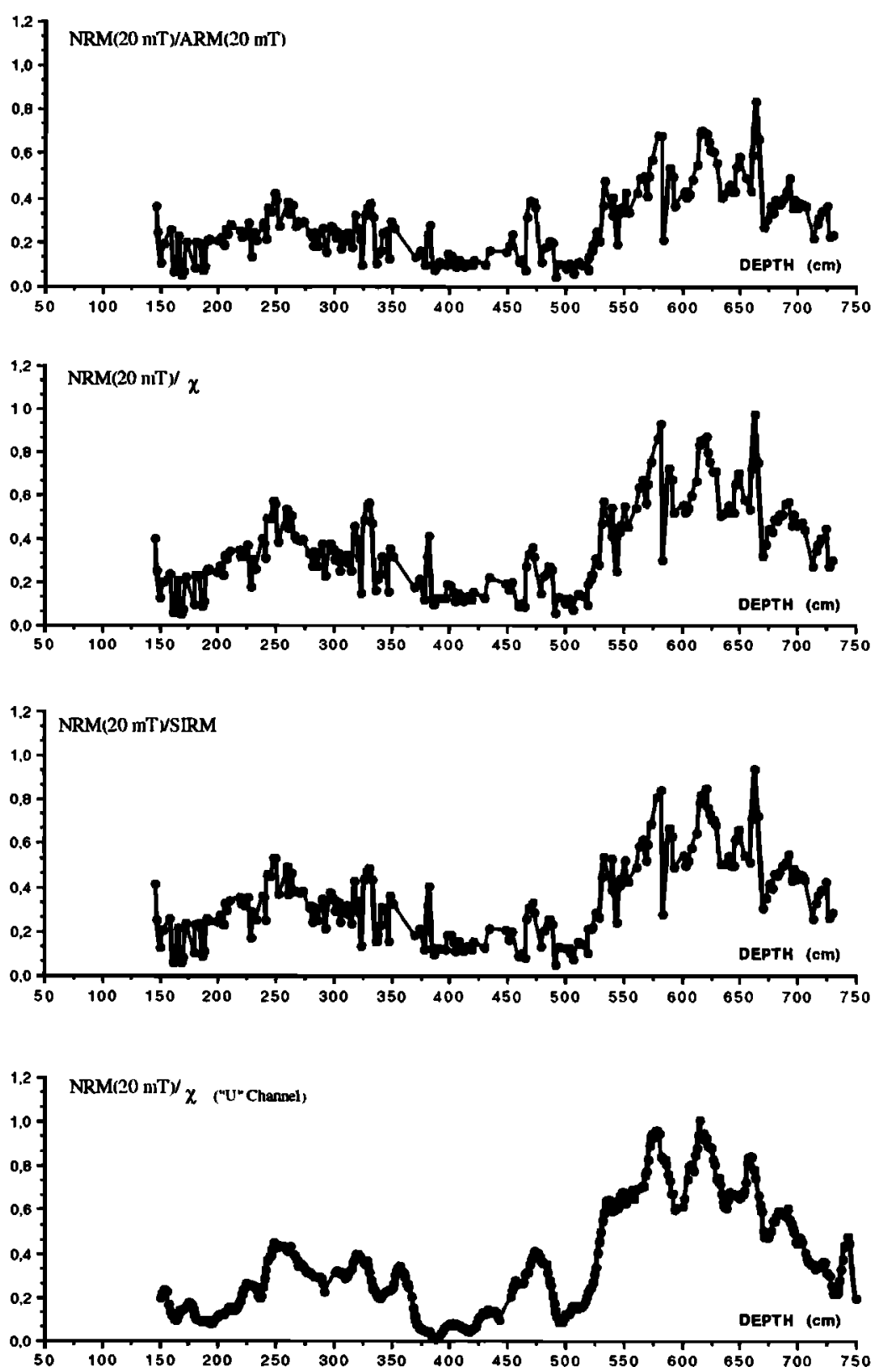

Fig. 7. Ratios of rock magnetic parameters for core MD 84 629. The similarity of the results for the four distinct ratios indicates that every set of measurements can be used as an estimate of relative paleointensity.

sites are located at the same latitude (within a few degrees). It is therefore valid to make direct comparisons between the raw magnetic field intensities deduced from this study and the virtual axial dipole moments calculated from the volcanic data by using an arbitrary scale factor.

The overall agreement between the two data sets plotted in Figure $12 a$ may be somewhat surprising since the volcanic records are very sensitive to the effects of the nondipole fields. Periods with multiple absolute paleointensities show, however, a dispersion which can reach about one fifth of the average field value. This variability is about the same order of magnitude as the present nondipole field intensity. If this explanation is correct, we should then observe a better agreement between both curves after averaging the volcanic records over intervals of 500 years to smooth the influence of nondipole field variations. It can be seen in Figure $12 b$ that, after smoothing, the curves then superimpose almost perfectly.

\section{DISCUSSION}

Unfortunately, the tops of the marine cores were either missing or partly disturbed, so that no record could be obtained for the period covering the last $8 \mathrm{kyr}$ and compared with the archeomagnetic data set compiled by McElhinny and Senanayake [1982]. However, the record is in excellent agreement with the rest of the archeomagnetic data set from 40 to $8 \mathrm{kyr}$ and confirms that a general increase of the field intensity prevailed for this period, culminating in a small intensity peak at $9 \mathrm{kyr}$ which has been reported in earlier studies of marine sediments from the Atlantic [Tauxe and Valet, 


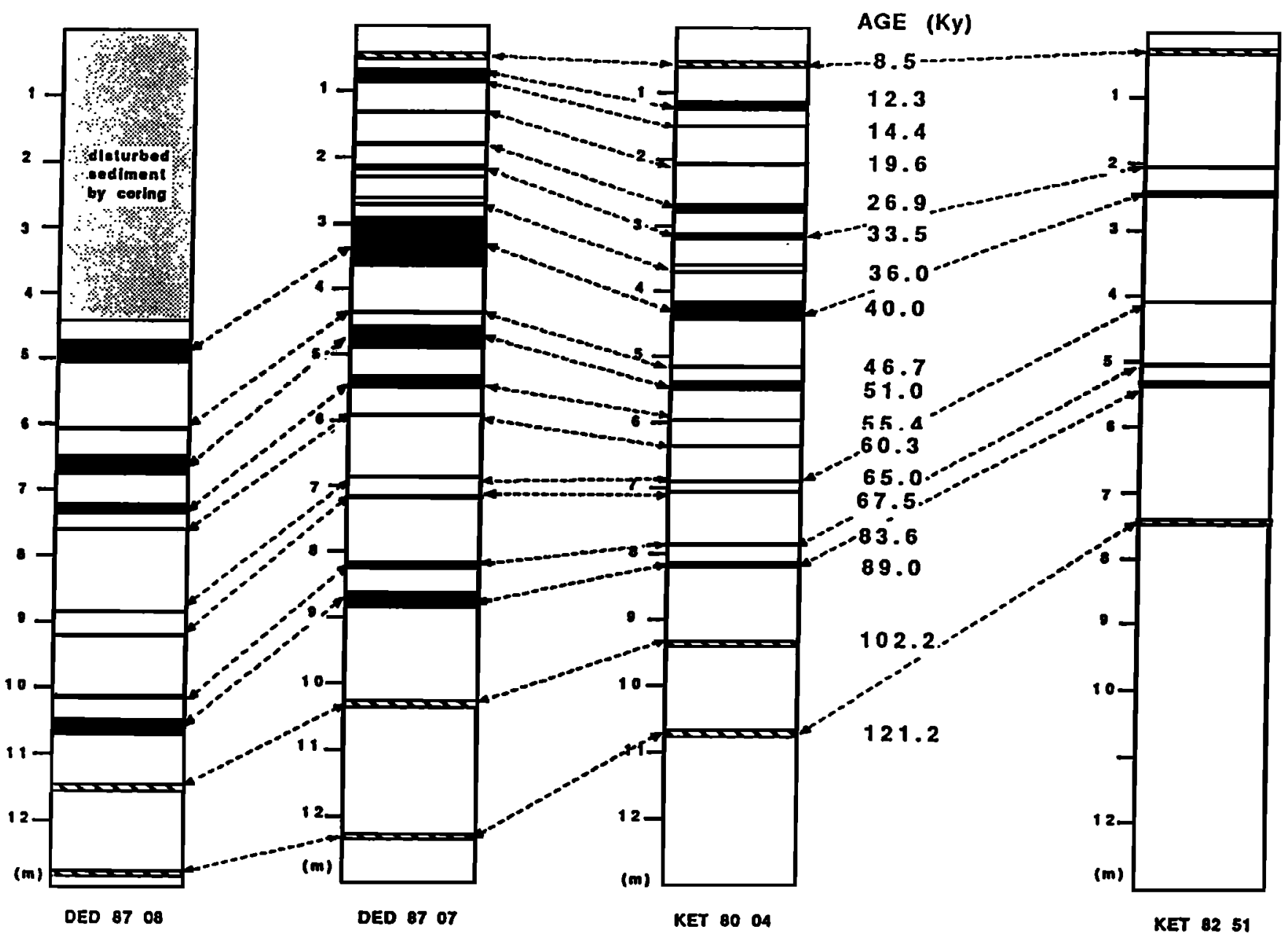

WDS Sapropel Layers

Main Tophre layers

Fig. 8a. Detailed correlations between the four cores from the Tyrrhenian Sea. The absolute time scale is provided by the complete oxygen record of core KET 8004, which was used as a reference [Paterne, 1985; Paterne et al., 1986; Paterne et al., 1988].

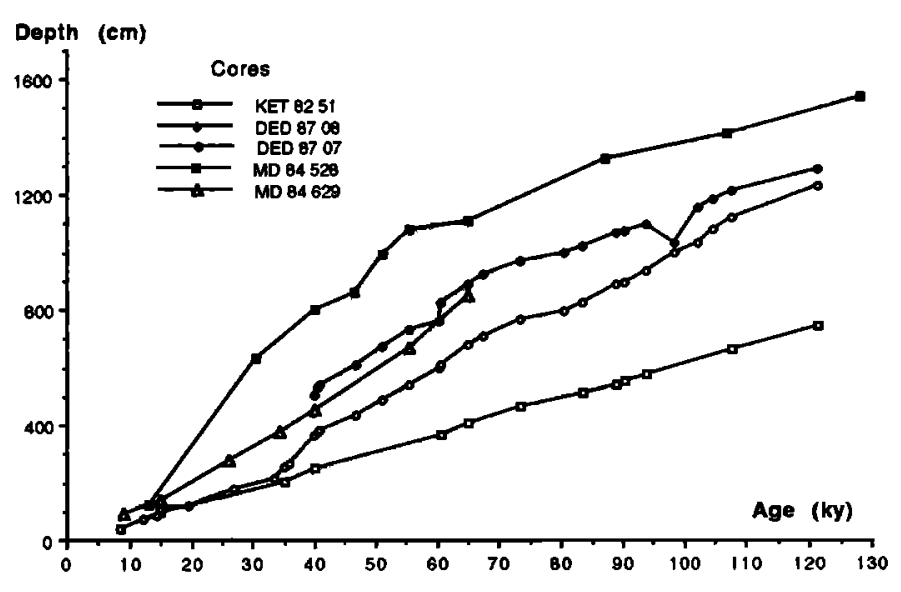

Fig. $8 b$. Variations in the deposition rates calculated within every successive dated level.
1989] and the Pacific oceans [Constable and Tauxe, 1987]. Such good agreement even on short time scales between remote records obtained from various media constitutes an additional indication of the ability of sediments to retain field intensity variations of relatively high frequency.

The new results obtained in this study indicate that a general field intensity increase has prevailed since $20 \mathrm{kyr}$ B.P. with a minimum value of $28 \%$ of the present field. Before this period the paleointensity curve depicts three major oscillations with significant drops occurring at 21,39 and $60 \mathrm{kyr}$. On average, the field value was lower by about a factor of 2 than the present intensity for the period 0-80 kyr.

The lowest dipole moment occurred at $39 \mathrm{kyr}$. Weak intensities and excursional directions were reported in the same time interval in France (Laschamp and Olby flows) [Bonhommet and Babkine,1967; Chauvin, 1989; Roperch and Bonhommet, 1982; Roperch et al., 19881 and in Iceland (Skalameifell excursion) [Levi et al., 1987; Marshall et al., 1988]. Although the datings of these lava flows agree reasonably well, the error bar inherent in the chronological data does not allow us to establish firmly that they were contemporaneous. No departure of the geomagnetic vector from 
TABLE 2. The Coefficient Correlations Between the Distinct Rock Magnetic Parameters for Core MD 84629

\begin{tabular}{ccccc}
\hline & NRM & ARM & $\chi$ & SIRM \\
\hline NRM & & & & \\
ARM & 0.1644 & & & \\
$\chi$ & 0.1432 & 0.6727 & & \\
SIRM & 0.2701 & 0.6463 & 0.9526 & \\
$\mathrm{O}^{18}$ & -0.4860 & 0.0306 & 0.1017 & 0.0311 \\
\hline
\end{tabular}

Probability limits for $n=201$ are $P$ 5\%: 0.1156; P 1\%: 0.1635; P 0.1\%:0.2162

the normal direction was observed during this period in the single samples from the marine cores involved in this study, which would mean that the duration of the event was less than 200 years. There is also no evidence for directional changes during this period in the high-resolution sedimentary sequence from Lac du Bouchet [Creer et al., 1986; Creer, 1989; Thouveny et al., 1990]. Discontinuities and/or breaks in the sedimentation could be responsible, but it is difficult to imagine that these phenomena occurred synchronously in different oceans, as well as in lacustrine sediments. Therefore, at least five high-resolution sedimentary records obtained from widely separated areas imply a very short duration of the Laschamp event which, even allowing for possible averaging effects due to postdepositional processes, cannot exceed a few hundred years. An implicit consequence is that the almost complete field reversal recorded at Laschamp and Olby has a duration lower by more than an order of magnitude than durations currently reported for the directional changes associated with reversals. It may thus be difficult to envisage that the Laschamp event was governed by similar processes.

Two regular and successive oscillations with similar amplitudes between 20-40 kyr and 40-60 kyr suggest the presence of sinusoidal variations with periodicities of about 20 kyr. Links between variations in the geomagnetic field and the Earth's orbital parameters have been suggested by several authors [Kent and Opdyke, 1977; Wollin et al., 1978; Negi and Tiwari, 1984]. Although the time constants observed in this study appear to be similar in magnitude to those involved in the precession of the Earth's orbit, the present record is far too short to establish the validity of a periodic cycle. The record begins at about $10 \mathrm{kyr}$, and the oldest part, between 60 and 80 kyr, is marked by a somewhat higher noise level.

Three independent paleointensity records have been obtained from the Pacific Ocean which cover long periods. Kent and Opdyke [1977] performed a statistical analysis of the NRM/ARM record from core RC10-167, located in the North Pacific, and found a dominant 43-kyr period during the last 700 kyr. Tauxe and $W u$ (1990) performed a new analysis of this record by taking into account the changes in the sedimentation rates (the previous time scale was based solely on the BrunhesMatuyama boundary) combined with two other cores (ERDC $113 p$ and $89 p$ comprised between 0 and $372 \mathrm{kyr}$ ) from the Ontong Java plateau [Constable and Tauxe, 1987], in the western equatorial Pacific. These authors found that a dominant frequency of around $33 \mathrm{kyr}$ (which is the same peak as detected by Kent and Opdyke taking into account the rescaling effects) prevailed for the last $350 \mathrm{kyr}$. However, this analysis has been performed over a very long period from records with a much lower resolution than that of the present study. A synthesis of the results from the North Pacific has been obtained by combining the results from box cores [Constable and Tauxe, 1987] and the record from piston cores [Tauxe and $W u, 1990]$. The result is in good agreement with the stacked record in Figure $12 c$. Within small phase shifts related to the uncertainties in the datings, identical variations are observed within the same time intervals. Only the oscillation between 20 and $30 \mathrm{kyr}$ is not obvious in the Pacific record ERDC 113p. This may be due to changes in the deposition rate, discontinuity between piston cores and box cores, and also a consequence of the very different average time resolution (by a factor of 8 ) between both records.

Based on these results it seems therefore that different periodicities could have prevailed at distinct epochs. There is a priori no apparent reason for suspecting stationary features of the geomagnetic field. However, the present data set is restricted to a limited number of cores, and a thorough investigation, from many regions, is now necessary to extend the analysis further back in time on a more global scale.

\section{CONCLUSION}

Relative paleointensity estimates of the geomagnetic field variations have been made from five marine cores distributed in the Tyrrhenian Sea, the eastern Mediterranean and the south Indian Ocean. Oxygen isotopes and tephrachronology provided independent time frameworks for the last $80 \mathrm{kyr}$. There is excellent agreement between the records when plotted on the same time scale, and features as short as 2 or $3 \mathrm{kyr}$ could be resolved with good precision. Little discrepancies found between the synthetic curve from Mediterranean records and the single record from the south Indian Ocean demonstrate the importance of acquiring distinct records from the same area in order to isolate the true dipolar field variations. The overall curve compares quite well with the global archeomagnetic data before $10 \mathrm{kyr}$ B.P. and provides an excellent fit to the sparse absolute paleointensities obtained from lava flows within the period 0-40 kyr. Two well-marked minima at which the geomagnetic field intensity fell to 22 and 28 percent of the present value occurred at 39 and $60 \mathrm{kyr}$, respectively. Interestingly, the low field values at $39 \mathrm{kyr}$ coincide with the period recording anomalous directions at Laschamp, but no directional change is apparent in the records. Although some evidence of a periodic cycle of $20 \mathrm{kyr}$ could be deduced from

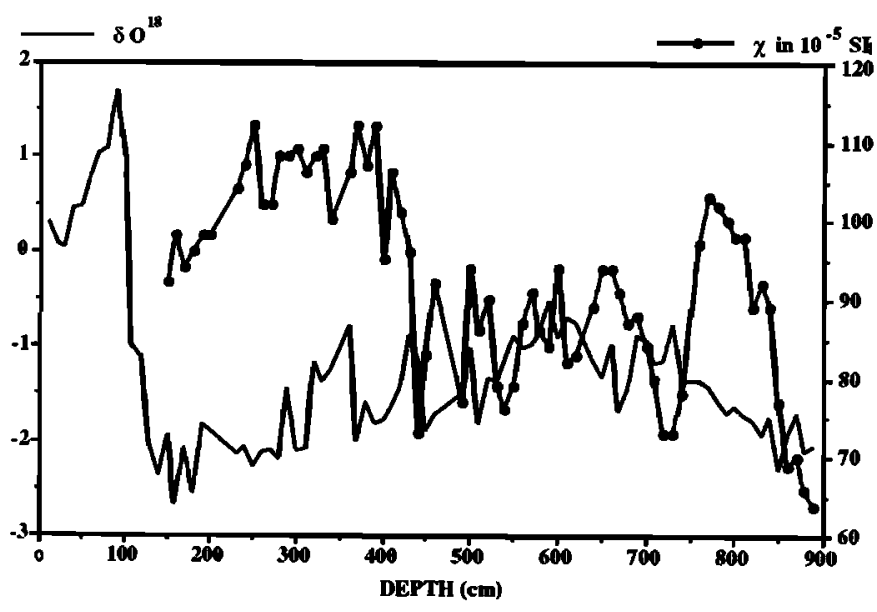

Fig. 9. Comparison between the $\delta^{18} \mathrm{O}$ and the low-field susceptibility records of core MD 84629. Some correlations could be present, but the amplitude of the variations does not account for major and long-term changes. 

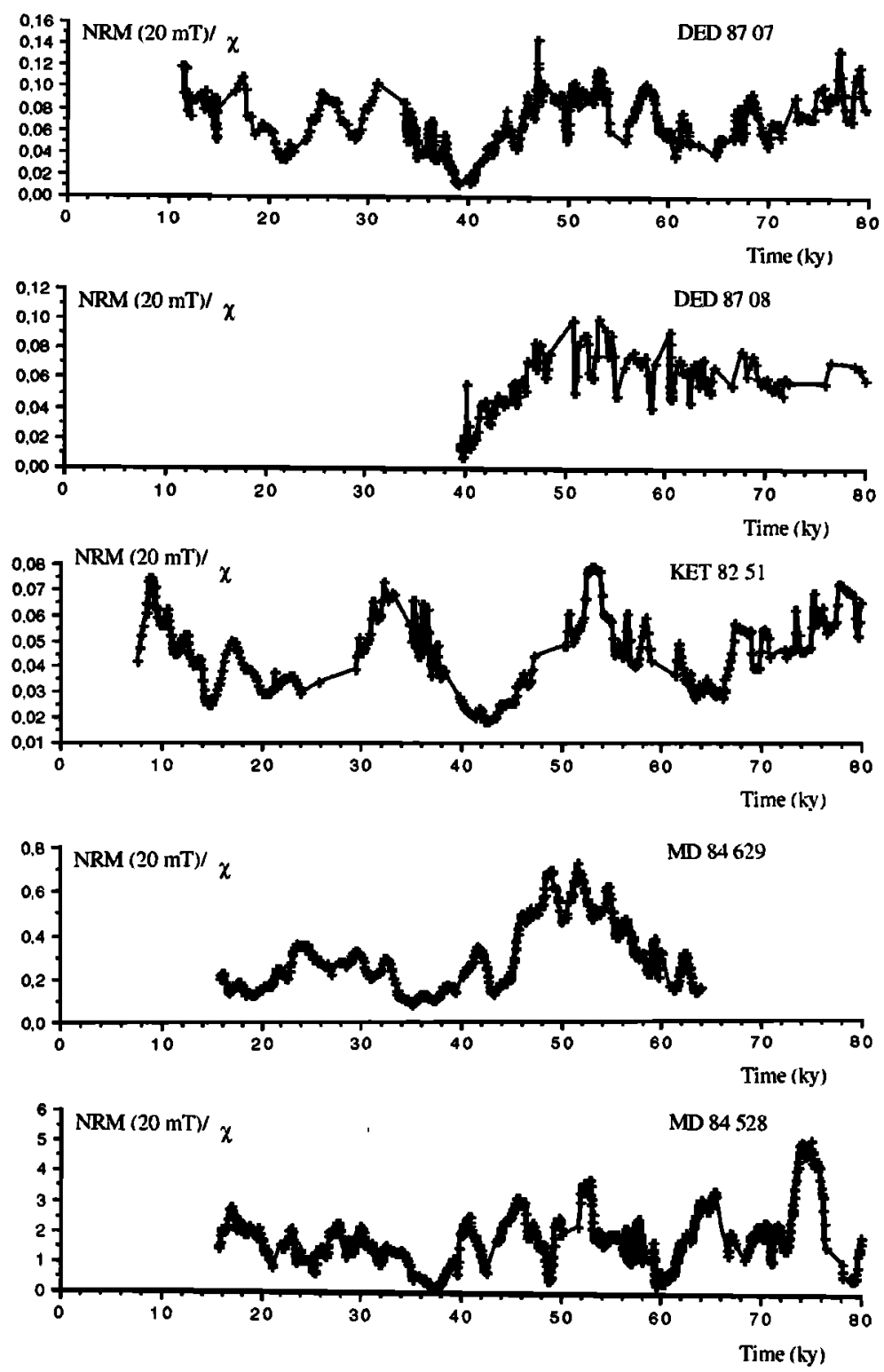

Fig. 10. Evolution of the NRM $(20 \mathrm{mT}) / \chi$ ratio plotted as a function of time. The vertical scales are arbitrary.

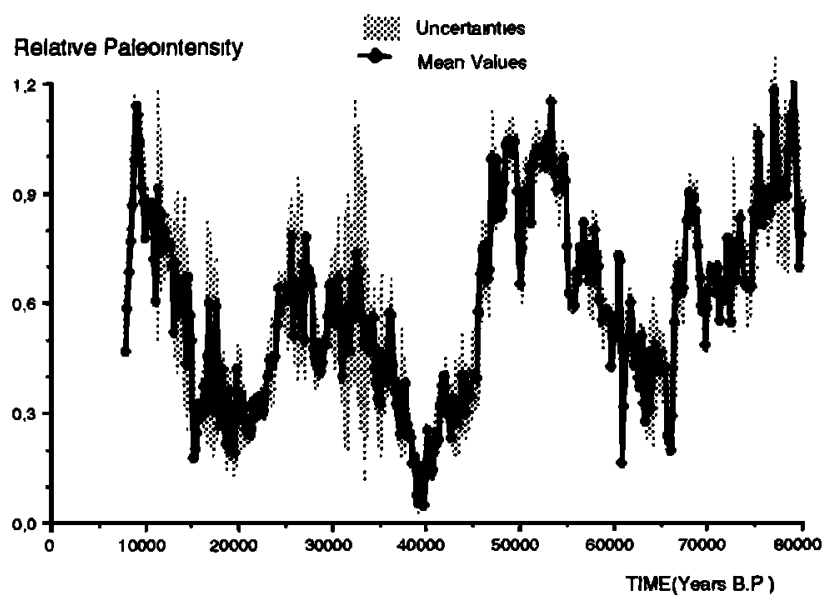

Fig. 11. Stacked record of the NRM(20mT)/ $\chi$ data calculated from the four scaled Mediterranean cores (DED 8707, DED 8708, KET 8251 and MD 84629). The envelope of the curve is delimited by the standard deviation from the mean of the measurements (within intervals of 200 years). This curve represents our best approximation of the relative field paleointensity. these data, the records are too short for establishing conclusive correlations with parameters linked to the Earth's orbit.

The present results also compare quite well with a paleointensity record from the western equatorial Pacific. This correlation can be envisaged as a first step towards the construction of a global paleointensity record of the dipole field. Indeed, the remarkable coherence between normalized intensity records from geographically distinct areas with different paleoenvironmental conditions demonstrates the potential of sediments as reliable recorders of relative variations of the geomagnetic field intensity.

Acknowledgments. The authors are pleased to acknowledge C. Laj, L. Hagee, R. Weeks for critical readings of the manuscript. D.C. Clark and $\mathrm{J}$. Tessier provided technical assistance. A. Mazaud and C. Jehanno provided generous assistance in various stages of this work. The marine cores used for this study were collected during cruises of the French oceanographic vessel Marion Dufresne (Terre Australes et Antartiques Françaises). This is CNRS-INSU DBT-Messages Sédimentaires contribution 313 and CFR contribution 1173. 
$\operatorname{VADM}\left(\times 10^{22} \mathrm{Axm}^{2}\right)$

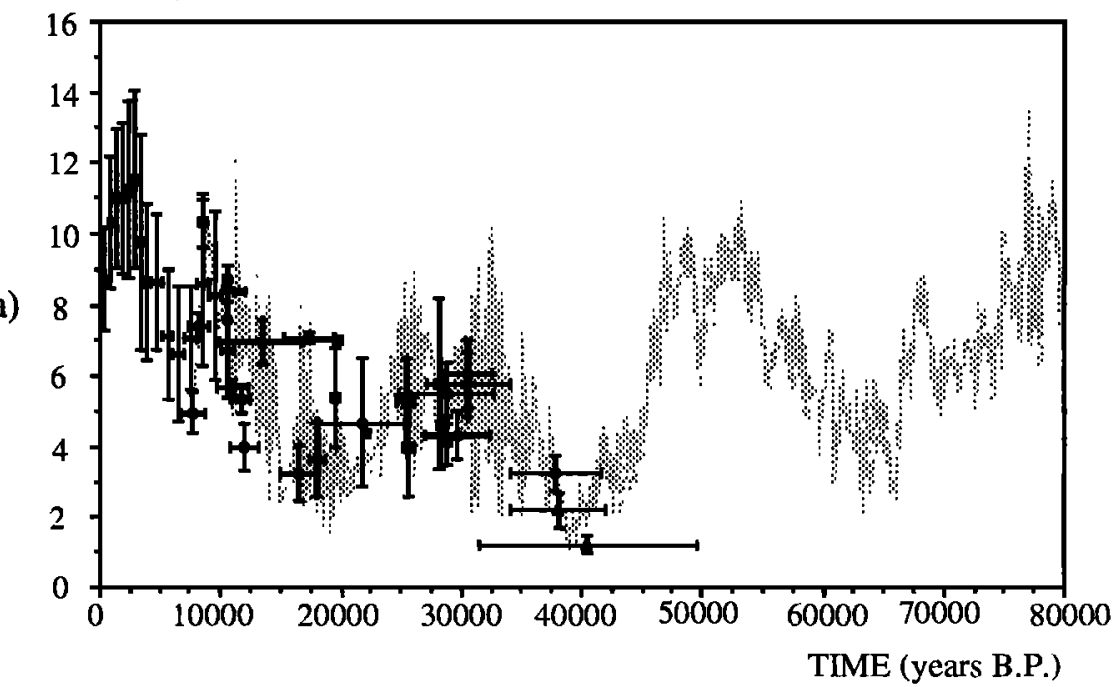

$\operatorname{VADM}\left(\times 10^{22} \mathrm{Axm}^{2}\right)$

b)

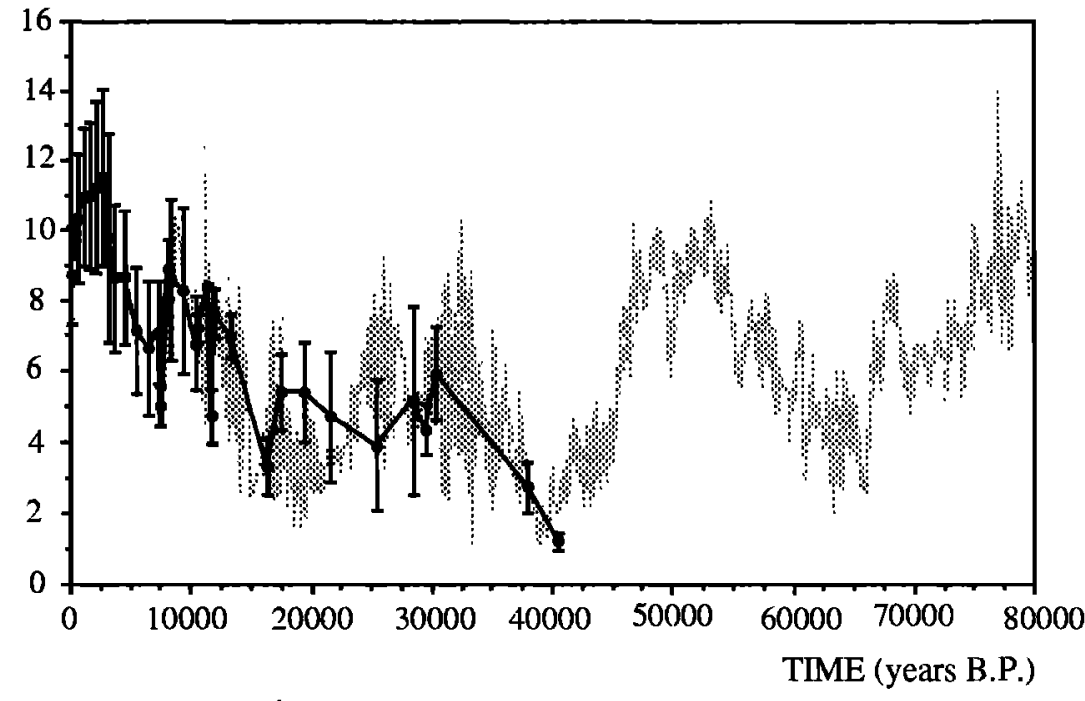

$\operatorname{VADM}\left(\mathrm{x}_{10}{ }^{22} \mathrm{Axm}^{2}\right)$

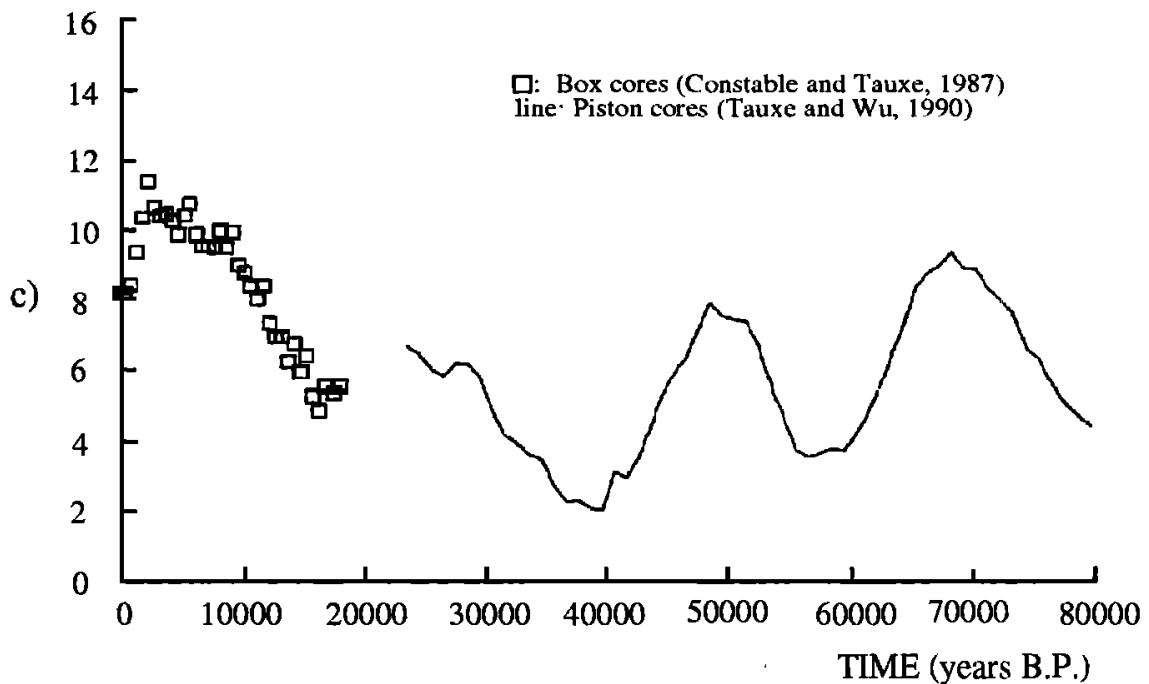

Fig. 12. (a) Comparison between the sedimentary records and the (archeomagnetic and) volcanic data sets available for the period 0-40 kyr. small square: Coe et al. [1978]; large square: Barbetti and Flude [1979]; small circle: McElhinny and Senanayake [1982]; large circle: Salis [1987]; small triangle: Roperch et al. [1988]; large triangle: Chauvin et al. [1991]. (b) The volcanic data averaged within intervals of 500 years. (c) Stack record obtained from piston cores ERDC113p in the eastern equatorial Pacific [Tauxe and $W u, 1990]$ and box cores in the North Pacific [Constable and Tauxe, 1987] 


\section{REFERENCES}

Barbetti, M. F., and K. Flude, Geomagnetic variation during the late Pleistocene period and changes in the radiocarbon time scale, Nature, 279, 202-205, 1979.

Barton, C. E., R. T. Merril, and M. F. Barbetti, Intensity of the Earth magnetic field over the last 10000 years, Phys. Earth Planet. Inter., 20, 96-110, 1979.

Bloemendal, J., B. Lamb, and J. King, Paleoenvironmental implications of rock-magnetic properties of late quaternary sediments cores from the eastern equatorial Atlantic, Paleoceanography, 3, 61-87, 1988.

Bonhommet, N., and J. Babkine, Sur la présence de directions inversées dans la chaîne du Puys, C. R. Acad. Sci., 264, 92-94, 1967.

Chauvin, A., Instabilité du champ magnétique terrestre en périodes stables et de transition, enregistrée par des séquences de coulées volcaniques du quaternaire,Thèse, Mémoires et documents du Centre Armoricain d'Etude Structurale des Socles, Rennes, France, 1989.

Chauvin, A., P. Y. Gillot, and N. Bonhommet, Paleointensity of the Earth's magnetic field recorded by two late quaternary volcanic sequences, at the island of La Réunion (Indian Ocean), J. Geophys. Res., 96, 1981-2006, 1991.

Cita, M. B., M. A. Chierici, G. Ciampo, M. Moncharmont Zei, W. F. B. Ryan, and R. Scorziollo, Quaternary record in the Ionian and Tyrrhenian basins of the Mediterranean Sea, Initial Rep. Deep Sea Drill. Proj., 13, 1263-1340, 1973.

Coe, R. S., S. Gromme, and E. A. Mankinen, Geomagnetic paleointensities for radiocarbon-dated lava flows on Hawaij and the question of the Pacific non-dipole low, J. Geophys. Res., 83, 1740-1756, 1978.

Constable, C. G., Eastern Australian geomagnetc field intensity over the past 14000 years, Geophys. J. R. Astron. Soc., 81, 121-130, 1985.

Constable, C. G., and L. Tauxe, Paleointensity in the pelagic realm: Marine sediment data compared with archeomagnetic and lake sediment records, Geophys. J. R. Astron. Soc., 90, 43-59, 1987.

Creer, K. M., The Lac du Bouchet paleomagnetic record: Its reliability and some inferences about the character of geomagnetic secular variations through the last 50000 years, in Geomagnetism and Paleomagnetism NATO ASI Series C Vol. 26I, edited by Lowes F. J. et al., pp. 71-90, Kluwer, Boston, Mass., 1989.

Creer, K. M., G. Smith, P. Tucholka, E. Bonifay, N. Thouveny, and E. Truze, A preliminary paleomagnetic study of the Holocene and late glacial sediments of Lac du Bouchet (Haute Loire), France, Geophys. J. R. Astron. Soc., 86, 943-964, 1986.

Imbrie, J., J. D. Hays, D. G. Martinson, A. Mc Intyre, A. C. Mix, J. J. Morley, N. G. Pisias, W. L. Prell, and N. J. Shackleton, The orbital theory of Pleistocene climate: Support from revised chronology of the marine ${ }^{18} \mathrm{O}$ record, in Milankovitch and Climate, edited by $\mathrm{A}$. Berger et al., pp. 269-305, D. Reidel , Hingham, Mass., 1982.

Johnson, H. P., H. Kinoshita, and R. T. Merril, Rock magnetism and paleomagnetism of some north Pacific deep-sea sediment cores, Geol. Soc. Am. Bull., 86, 412-420, 1975.

Kawai, N. and T. Nakajima, Secular variation in the recent 60.000 years found from the Lake Biwa sediments, in Rock magnetism and Paleogeophysics, pp. 34-38, Rock Magnetism and Paleogeophysics Research, Group, Tokyo, Japan, 1973.

Kent, D. V., and N. D. Opdyke, Paleomagnetic field intensity variation recorded in a Brunhes Epoch deep-sea sediment core, Nature, 266, $57,1977$.

King, J.W., S. K. Banerjee, J. Marvin, and O. Ozdermir, A comparison of different magnetic methods for determining the relative grain size of magnetite in natural materials: Some results from lake sediments, Earth Planet. Sci. Lett., 59, 404-419, 1982.

King, J.W., S. K. Banerjee, and J. Marvin, A new rock magnetic approach to selecting sediments for geomagnetic paleointensity studies: Application to paleointensity for the last 4000 years, $J$. Geophys. Res., 88, 5911-5921, 1983.

Kovacheva, M., Summarized results of the archeomagnetic investigation of the geomagnetic field variation for the last 8000 years in south-eastern Europe, Geophys. J. R. Astron. Soc., 61, 57-64, 1980.

Kovacheva, M., Archeomagnetic investigation of geomagnetic secular variations, Philos. Trans. R. Soc. London, Ser. A, 306, 79-86, 1982.
Laj, C., S. Guitton, C. Kissel, and A. Mazaud, Complex behavior of the geomagnetic field during three successive polarity reversals, $J$. Geophys. Res., 93, 11,655-11,666, 1988.

Levi, S., and S. K. Banerjee, On the possibility of obtaining relative paleointensities from the lake sediments, Earth Planet. Sci. Lett., $29,219-226,1976$

Levi, S., S. H. Audunsson, and R. A. Duncan, The geomagnetic excursion at Skalamaelifell, Iceland: Additional evidence for unstable geomagnetic behavior circa $40 \mathrm{Kyr}$ ago, Eos Trans. AGU," $68,1249,1987$.

Marshall, M., A. Chauvin, and N. Bonhommet, Preliminary paleointensity measurements and detailed magnetic analyses of basalts from the Skalamaelifell, South West Iceland, J. Geophys. Res., 93, 11,681-11,698, 1988.

McElhinny, M. W., and W. E. Senanayake, Variations in the geomagnetic diplole. I, The past 50000 years, J. Geomagn. Geoelectr., 34, 39-51, 1982.

Negi, J. G., and R. K. Tiwari, Periodicities of paleomagnetic intensity and paleoclimatic variations: A Walsh spectral approach, Earth Planet. Sci. Lett., 70, 139-147, 1984.

Nesbitt, J. D., Variation of the ratio intensity to susceptibility in red sandstones, Nature, 210, 618-620, 1966.

Opdyke, N. D., D. V. Kent, and W. Lowrie, Details of magnetic polarity transitions recorded in a high deposition rate deep-sea core, Earth Planet. Sci. Lett., 20, 315-324, 1973.

Paterne, M., Reconstruction de l'activité explosive des volcans de l'Italie du sud par téphrochronologie marine, Thèse, Université Paris XI, Orsay, France, 1985.

Paterne, M., F. Guichard, J. Labeyrie, P. Y. Gillot, and J. C. Duplessy, Tyrrhenian sea tephrochronology of the oxygen isotope records for the past 60,000 years, Mar. Geol., 72, 259-285, 1986.

Paterne, M., F. Guichard, and J. Labeyrie, Explosive activity of the south Italian volcanoes during the past 80.000 years as determined by marine tephrochronology, J. Volcanol. Geotherm. Res., 34, 153-172, 1988.

Petersen, N., T. V. Dobeneck, and H. Vali, Fossil bacterial magnetite in deep-sea sediments from the South Atlantic Ocean, Nature, 17, $611-615,1986$.

Robinson, S. G., The late Pleistocene paleoclimatic record of North Atlantic deep-sea sediments revealed by mineral-magnetic measurements, Phys. Earth Planet. Inter., 42, 22-47, 1986.

Roperch, P., and N. Bonhommet, Baked contact test and paleointensity results from the Laschamp-Olby flows, Eos Trans. AGU, 63, 1283, 1982.

Roperch, P., N. Bonhommet, and S. Levi, Paleointensity of the Earth's magnetic field during the Laschamp excursion and its geomagnetic implications, Earth Planet. Sci. Lett., 88, 209-219, 1988.

Ryan, W. F. B., Stratigraphy of late Quaternary sediments in the eastern Mediterranean, in The Mediterranean Sea, edited by D. J. Stanley, pp. 149-170, Dowden, Hutchinson and Ross, Stroudsburg, Pennsylvania, 1972.

Salis, J. S., Variation séculaire du champ magnétique terrestre. Directions et paléointensités sur la période $7000-70000$ ans P. B., dans la chaine de Puys, Mémoires et documents du Centre Armoricain d'Etude Structurale des Socles, Rennes, France, 1987.

Tauxe, L., and J. P. Valet, Relative paleointensity of the Earth's magnetic field from marine sedimentary records: A global perspective, Phys. Earth Planet. Inter., 56, 59-68, 1989.

Tauxe, L., and G. Wu, Normalized remanence in sediments of the western equatorial Pacific: Relative paleointensity of the geomagnetic field?, J. Geophys. Res., 95, 12,337-12,350, 1990.

Tauxe, L., J. L. Labrecque, R. Dodson, and M. Fuller, A new technique for paleomagnetic analysis of hydraulic piston core, Eos Trans. $A G U, 64,219,1983$.

Thouveny, N., K. M. Creer, and I. Blunk, Extension of the Lac do Bouchet paleomagnetic record over the last 120,000 years, Earth Planet. Sci. Lett., 97, 140-161, 1990.

Tucholka, P., M. Fontugne, F. Guichard, and M. Paterne, The Blake magnetic polarity episode in cores from the Mediterranean Sea, Earth Planet. Sci. Lett., 86, 320-326, 1987.

Valet, J. P., C. Laj, and C. G. Langereis, Sequential geomagnetic reversals recorded in upper Tortonian marine clays in western Crete (Greece), J. Geophys. Res., 93, 1131-1151, 1988.

Wollin, G., W. B. F. Ryan, and D. B. Ericson, Climatic changes, magnetic intensity variations and fluctuations of the eccentricity of the Earth's orbit during the past 2000000 years and a 
mechanism which may be responsible for the relationship, Earth

Planet. Sci. Lett., 41, 395-397, 1978.

M. Fontugne, F. Guichard, L. Labeyrie, M. Paterne and E. Tric, Centre des Faibles Radioactivités, laboratoire mixte CNRS-CEA, 91198 Gif-sur-Yvette Cedex, France.

P. Tucholka, Laboratoire de Géophysique, Bat. 509. Université Paris XI, 91405 Orsay Cedex, France.
L. Tauxe, Geological Research Division, Scripps Institution of Oceanography, La Jolla, CA 92093, USA.

J.:P. Valet, Institut de Physique du Globe, Tour 14-24, 4 Place Jussieu, 75252 Paris Cedex 05, France.

(Received November 12, 1990;

revised May 6, 1991;

accepted June 14, 1991.) 